\title{
STATISTIČKA ANALIZA KRETANJA BROJA NOVIH ČLANOVA OBVEZNIH MIROVINSKIH FONDOVA I UPLATA DOPRINOSA U DRUGI STUP MIROVINSKOG OSIGURANJA U REPUBLICI HRVATSKOJ (2011. - 2020.)
}

\begin{abstract}
Sažetak
Mirovinski fondovi predstavljaju značajne institucionalne investitore u Republici Hrvatskoj, kojima investicijski potencijal kontinuirano raste. U posljednjih desetak godina udio njihove imovine u ukupnoj imovini financijskog sustava porastao je s nešto manje od $5 \%$ na $17 \%$, dok imovina obveznih mirovinskih fondova čini oko $27 \%$ hrvatskog BDP-a. Članstvo u obveznim mirovinskim fondovima obvezno je za zaposlene osobe mlađe od 40 godina, a sredstva koja se izdvajaju na temelju doprinosa za mirovinsko osiguranje iznose 20 $\%$ bruto plaće zaposlenika. Ta se sredstva izdvajaju tako da se $15 \%$ izdvaja u prvi stup obveznog mirovinskog osiguranja na temelju generacijske solidarnosti (MIO I), a 5 \% u drugi stup obveznog mirovinskog osiguranja na temelju individualne kapitalizirane štednje (MIO II). U ovome radu napravljena je statistička analiza kretanja broja članova u obveznim mirovinskim fondovima (OMF) kao i dinamika uplata doprinosa za mirovinsko osiguranje na temelju individualne kapitalizirane štednje u drugi stup mirovinskog osiguranja (MIO II) u RH za razdoblje od 2011. do 2020., kao i međusobni odnos i utjecaj promatranih varijabli.

Ključne riječi: mirovinski fondovi, mirovinsko osiguranje, generacijska solidarnost, kapitalizirana štednja
\end{abstract}

\section{Uvod}

Podaci o broju članova u obveznim mirovinskim fondovima (OMF) i uplatama doprinosa za mirovinsko osiguranje na temelju individualne kapitalizirane štednje (MIO II) u Republici Hrvatskoj sustavno se prikupljaju od 2002., statistički i analitički

\footnotetext{
* Tamara Dajak, bacc.oec, REGOS-Središnji registar osiguranika, tamaradajak@gmail.com

** mr. sc. Milan Papić, Libertas međunarodno sveučilište, mpapic@libertas.hr

*** mr. sc. Nenad Vudrić, Libertas međunarodno sveučilište, nvudric@libertas.hr
} 
obrađuju te se rezultati redovito objavljuju na mrežnim stranicama Središnjeg registra osiguranika (REGOS). Time su informacije kojima REGOS raspolaže dostupne javnosti i zainteresiranim korisnicima.

Svrha je ovoga rada sustavno praćenje i statistička analiza priljeva novih članova obveznih mirovinskih fondova i uplata doprinosa za mirovinsko osiguranje na temelju individualne kapitalizirane štednje po godinama. Periodične promjene analizirane su kroz bazne i verižne indekse te prognostičke trend modele. Primjenom korelacijske i regresijske analize ispitana je povezanost promatranih varijabli kako bi se na temelju dobivenih rezultata mogli izvesti određeni zaključci u svrhu poduzimanja aktivnosti koje bi rezultirale većom mirovinom koja će se isplaćivati osiguraniku iz mirovinskog doprinosa na temelju individualne kapitalizirane štednje. Prilikom izračuna statističkih pokazatelja za razdoblje od 2011. do 2020. korišteni su podaci koji su objavljeni i javno dostupni na mrežnim stranicama REGOS-a.

\section{Središnji registar osiguranika}

Središnji registar osiguranika - REGOS institucija je u funkciji građana. Kao institucija javne uprave u svakodnevnom poslovanju REGOS se bavi vođenjem i održavanjem registra podataka o doprinosima za obvezna mirovinska osiguranja po osiguranicima, izborom i promjenom obveznog mirovinskog fonda, evidencijom uplaćenih doprinosa te prikupljanjem i kontrolom podataka po osiguranicima za obvezna mirovinska osiguranja kao i prosljeđivanjem uplata doprinosa MIO II u obvezne mirovinske fondove.

Način rada i poslovanja REGOS-a transparentan je prema javnosti te je u skladu s poslovnim procesima sustava upravljanja kvalitetom prema normi ISO 9001:2015, a reguliran je Zakonom o Središnjem registru osiguranika. Osnivač REGOS-a je Republika Hrvatska, odnosno Vlada Republike Hrvatske te REGOS za svoj rad odgovara Vladi Republike Hrvatske kojoj najmanje jednom godišnje, kao i Hrvatskoj agenciji za nadzor financijskih usluga (HANFA), podnosi izvješće o radu.

\section{Obvezni mirovinski fond}

Mirovinsko osiguranje na temelju individualne kapitalizirane štednje (MIO II) u Republici Hrvatskoj uređeno je Zakonom o obveznim mirovinskim fondovima, Zakonom o mirovinskom osiguranju, Zakonom o mirovinskim osiguravajućim društvima i pripadajućim podzakonskim aktima.

Obvezni mirovinski fond (OMF) je fond u koji poslodavac uplaćuje doprinos za mirovinsko osiguranje na temelju individualne kapitalizirane štednje za svoje zapo- 
slenike iz kojeg će se financirati dio mirovine iz drugog stupa mirovinskog osiguranja (MIO II). Postoje četiri obvezna mirovinska fonda koji sredstva osiguranika uplaćena na ime doprinosa na temelju individualne kapitalizirane štednje ulažu u razne korporativne i državne vrijednosne papire. Ulaganjima se sredstva kapitaliziraju i ostvaruju prinos svojim članovima kako bi prikupljena sredstva, nakon što se steknu uvjeti za umirovljenje, imala veću vrijednost. Isplatu mirovina korisniku mirovine, članu obveznog mirovinskog fonda, $\mathrm{u}$ okviru obveznog mirovinskog osiguranja na temelju individualne kapitalizirane štednje, obavljaju mirovinska osiguravajuća društva, doživotno ili privremeno, u skladu s prenesenim sredstvima iz obveznog mirovinskog fonda (Hrvatska agencija za nadzor financijskih usluga).

\section{1. Članstvo u obveznom mirovinskom fondu}

Članstvo u OMF-u obvezno je za zaposlene osobe mlađe od 40 godina. Zaposlenici mogu odabrati obvezni mirovinski fond od dostupna četiri OMF-a, od kojih svaki ima tri kategorije (A, B i C) koje se razlikuju prema svojoj investicijskoj strategiji, u koji će se uplaćivati doprinos za mirovinsko osiguranje na temelju individualne kapitalizirane štednje. Ako zaposlenik u zakonskom roku ne odabere obvezni mirovinski fond, REGOS ga po službenoj dužnosti raspoređuje u jedan od njih.

Završetkom prijave (osobni izbor ili službeni raspored) inicira se otvaranje osobnog računa člana obveznog mirovinskog fonda. Osiguranik može biti članom samo jednoga obveznog mirovinskog fonda i imati samo jedan osobni račun u obveznom mirovinskom fondu. Sredstva uplaćena na ime doprinosa na temelju individualne kapitalizirane štednje osobna su imovina svakog člana fonda i u slučaju smrti člana fonda predmet su nasljeđivanja (Središnji registar osiguranika).

Obvezni mirovinski fond osniva mirovinsko društvo koje upravlja njime u svoje ime i za račun članova obveznog mirovinskog fonda. Četiri obvezna mirovinska fonda na dan 31. prosinca 2020. ukupno su imali 2057391 člana. Broj novih članova OMF-a sustavno se prati od 1 siječnja 2002. kada je na snagu stupila mirovinska reforma po kojoj se, između ostalog, doprinos za mirovinsko osiguranje počeo razdvajati na doprinos za mirovinsko osiguranje na temelju generacijske solidarnosti (MIO I) i doprinos na temelju individualne kapitalizirane štednje (MIO II) i to za osiguranike mlađe od 40 godina. Kretanje broja novih članova OMF-a prikazuje grafikon 1 .

Dotadašnje izdvajanje za doprinos za mirovinsko osiguranje od $20 \%$ bruto osnovice plaće počelo se razdvajati tako da se $15 \%$ izdvaja u MIO I, takozvani prvi stup mirovinskog osiguranja, a 5 \% se izdvaja u MIO II, drugi stup mirovinskog osiguranja.

Iz podataka o priljevu novih članova OMF-a vidljivo je da se pad broja novih članova poklapa s padom BDP-a, odnosno s razdobljem recesije, kao i s razdobljem 
pandemije COVID-19 što je i logično jer u uvjetima lošeg gospodarskog rasta i recesije nema ni zapošljavanja, a samim time ni novih članova OMF-a.

Grafikon 1. Kretanje broja novih članova OMF-a u razdoblju 2011. - 2020.

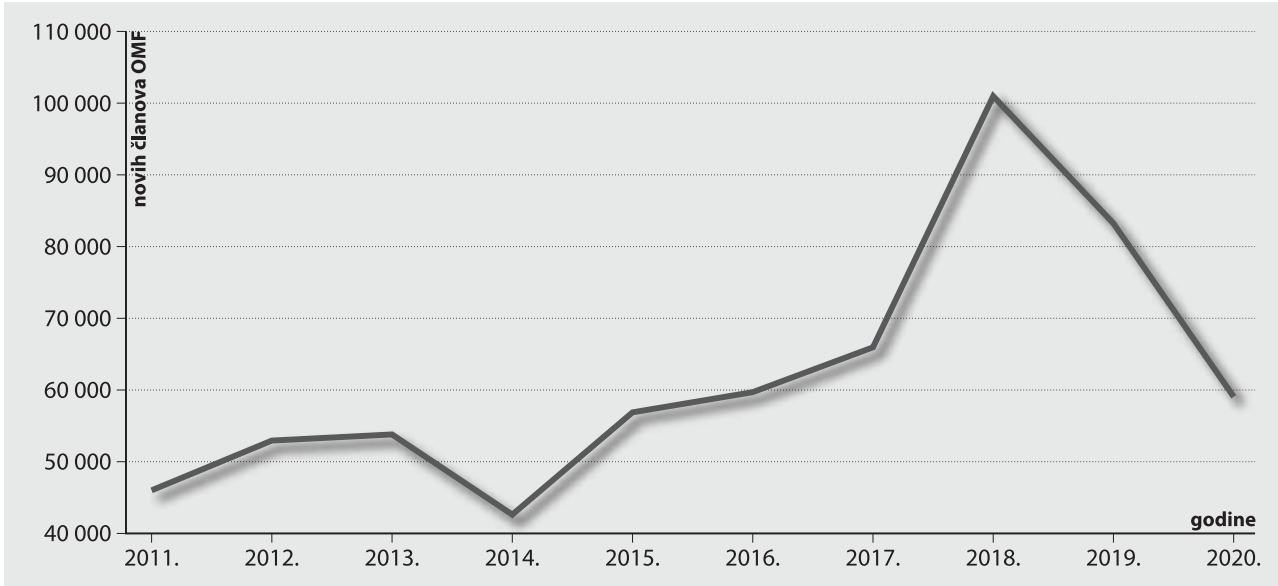

\section{Analitika broja novih članova OMF-a}

\subsection{Verižni indeksi}

Verižni ili lančani indeks pokazuje relativnu promjenu pojave u tekućem razdoblju u odnosu na prethodno razdoblje. To je postotni udio vrijednosti određene pojave u tekućem razdoblju u odnosu na vrijednost te pojave u prethodnom razdoblju (Papić, 2014).

Tablica 1. Verižni indeksi i stope promjene kao pokazatelj kretanja broja novih članova OMF-a u RH u razdoblju od 2011. do 2020.

\begin{tabular}{|cccc|}
\hline Godina & $\begin{array}{r}\text { Broj novih članova } \\
\text { OMF-a }\end{array}$ & Verižni indeks & Stopa promjene \\
\hline 2011. & 46217 & - & - \\
\hline 2012. & 52995 & 114,67 & 14,67 \\
\hline 2013. & 53825 & 101,57 & 1,57 \\
\hline 2014. & 42727 & 79,38 & $-20,62$ \\
\hline 2015. & 56988 & 133,38 & 33,38 \\
\hline 2016. & 59893 & 105,10 & 5,10 \\
\hline 2017. & 65940 & 110,10 & 10,10 \\
\hline 2018. & 101181 & 153,44 & 53,44 \\
\hline 2019. & 83354 & 82,38 & $-17,62$ \\
\hline 2020. & 59267 & 71,10 & $-28,90$ \\
\hline
\end{tabular}


Vidljivo je da od 2012. do 2018. (osim u 2014.) raste broj novih članova OMF-a, dok u zadnjim dvjema godinama promatranog razdoblja taj broj pada.

Grafikon 2. Kretanje broja novih članova OMF-a u RH u periodu od 2011. do 2020. (verižni indeksi)

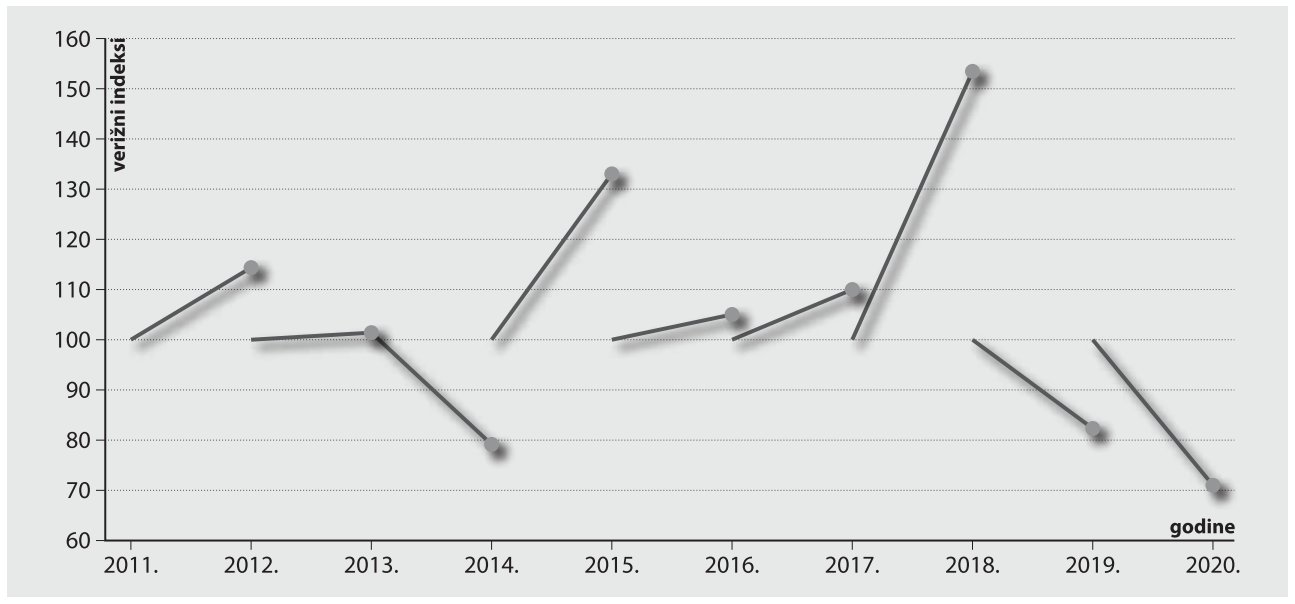

\subsection{Bazni indeksi}

Bazni indeksi pokazuju relativne promjene u tekućem razdoblju u odnosu na neko odabrano bazno razdoblje. Bazni indeks je postotni udio vrijednosti određene pojave u odnosu na vrijednost te pojave u baznom razdoblju (Papić, 2014).

Tablica 2. Bazni indeksi i stopa promjene kao pokazatelj kretanja broja novih članova OMF-a u RH u razdoblju od 2011. do 2020.

\begin{tabular}{|cccc|}
\hline Godina & $\begin{array}{r}\text { Broj novih članova } \\
\text { OMF-a }\end{array}$ & $\begin{array}{c}\text { Bazni indeksi }(2011= \\
100)\end{array}$ & Stopa promjene \\
\hline 2011. & 46217 & 100 & 0 \\
\hline 2012. & 52995 & 114,67 & 14,67 \\
\hline 2013. & 53825 & 116,46 & 16,46 \\
\hline 2014. & 42727 & 92,45 & $-7,55$ \\
\hline 2015. & 56988 & 123,31 & 23,31 \\
\hline 2016. & 59893 & 129,59 & 29,59 \\
\hline 2017. & 65940 & 142,67 & 42,67 \\
\hline 2018. & 101181 & 218,93 & 118,93 \\
\hline 2019. & 83.354 & 180,35 & 80,35 \\
\hline 2020. & 59267 & 128,24 & 28,24 \\
\hline
\end{tabular}

Iz dobivenih vrijednosti može se zaključiti da je npr. 2018. bilo $118,93 \%$ više novih članova OMF-a u odnosu na baznu 2011., dok je 2020. bilo tek $28,24 \%$ više novih članova OMF-a u odnosu na istu, 2011. 
Grafikon 3. Kretanje broja novih članova OMF-a u RH u razdoblju od 2011. do 2020.

(bazni indeksi)

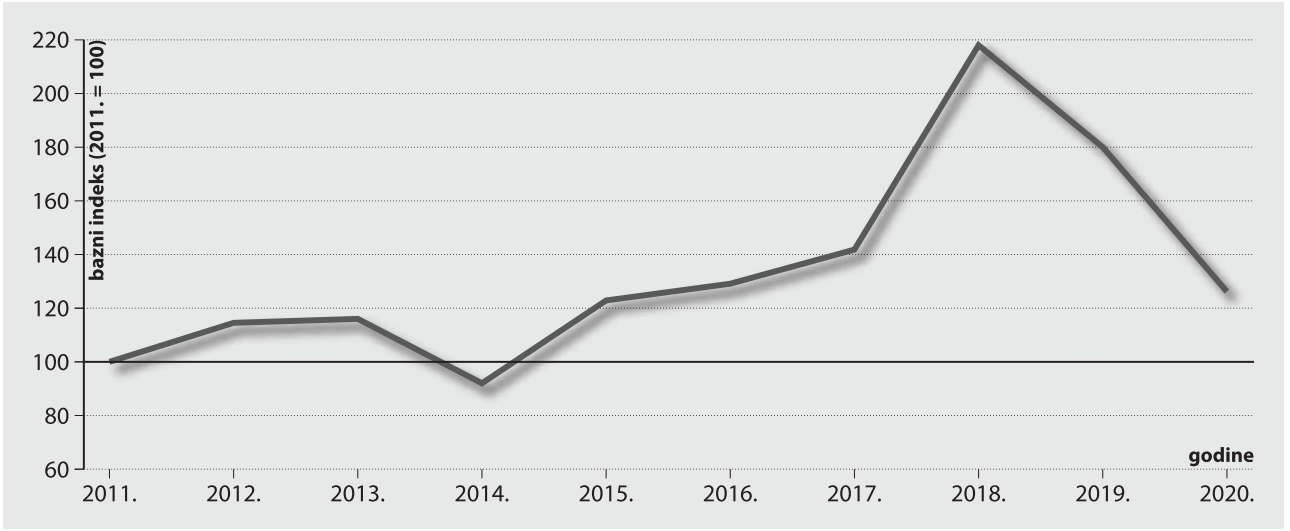

\subsection{Prognostički trend modeli}

Prognostički trend modeli jedan su od načina koji se koriste za analizu vremenskih nizova. Kod trend modela nezavisna varijabla uvijek je vrijeme, u ovome slučaju izraženo u godinama. Zavisna varijabla bit će broj novih članova OMF-a. Promatrat će se promjena vrijednosti zavisne varijable, broja novih članova OMF-a, po godinama i to tijekom 10 godina. Kretanje promatrane pojave može se prikazati pomoću odgovarajućeg trend modela. Ukoliko postoji neka pravilnost u promjenama vrijednosti promatrane pojave $\mathrm{u}$ određenom vremenskom razdoblju (vremenski niz ima tendenciju rasta ili pada), kažemo da niz ima trend (Papić, 2014).

Za navedene podatke izračunati su parametri linearnog i eksponencijalnog trend modela te njihove mjere reprezentativnosti. Pokazalo se da je eksponencijalni trend model reprezentativniji (veći je pripadajući koeficijent determinacije) te u ovom radu detaljnije opisujemo taj model.

Grafikon 4. Kretanje broja novih članova OMF-a (eksponencijalni trend model)

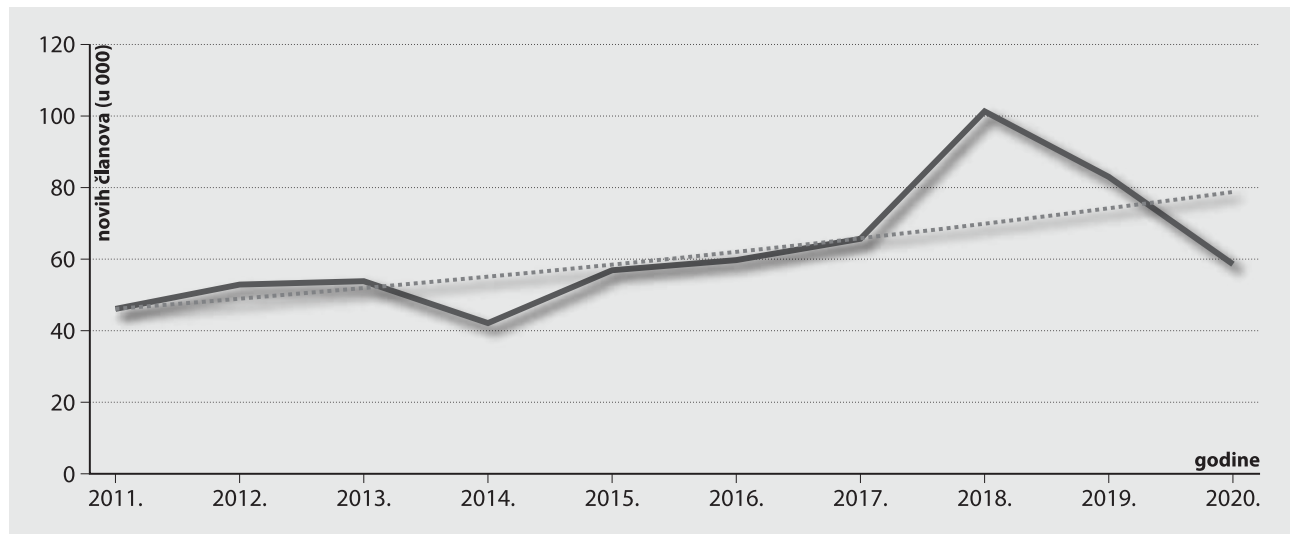


Jednadžba eksponencijalnog trend modela (nakon izračuna parametra b; standardni oblik $\left.Y=a \cdot b^{x}\right)$ glasi:

$$
Y=45998 \cdot 1,0618^{x}
$$

Trend vrijednost za ishodišnu 2011. iznosi 45998 novih članova OMF-a.

U promatranom razdoblju svake se godine broj novih članova OMF-a u prosjeku povećavao 1,062 puta, odnosno 6,2\%. Reprezentativnost eksponencijalnog trend modela očitava se iz koeficijenta determinacije $\left(\mathrm{R}^{2}=0,49\right)$, iz čega slijedi da je $49 \%$ periodičnih promjena broja novih članova OMF-a u RH u periodu od 2011. do 2020. objašnjeno eksponencijalnim trend modelom. Dodatnom provjerom ustanovljeno je da je dobiveni trend model statistički značajan $(\mathrm{p}<0,05)$. Treba napomenuti da je reprezentativnost dobivenog modela u određenoj mjeri narušena padom broja novih članova OMF-a u zadnjim dvjema godinama promatranog razdoblja.

\subsection{Prognoza vrijednosti broja novih članova OMF-a za period od 2021. do 2025.}

Prognoza vrijednosti promatrane varijable za određeni vremenski interval na temelju eksponencijalnog trenda određuje se pomoću funkcije u MS Excelu GROWTH, tako da se promatrano razdoblje poveća za određeni broj godina. Prognozirane vrijednosti broja novih članova OMF-a, na temelju utvrđenog trenda, u narednom periodu od 2021. do 2025. prikazane su u tablici 3.

Tablica 3. Prognoza broja novih članova OMF-a na temelju eksponencijalnog trenda za razdoblje od 2021. do 2025.

\begin{tabular}{|c|c|}
\hline Godina & Broj novih članova OMF \\
\hline 2011. & 46217 \\
\hline 2012. & 52995 \\
\hline 2013. & 53825 \\
\hline 2014. & 42727 \\
\hline 2016. & 56988 \\
\hline 2017. & 59893 \\
\hline 2018. & 65940 \\
\hline 2019. & 101181 \\
\hline 2020. & 83354 \\
\hline 2021. & 59267 \\
\hline 2022. & 83895 \\
\hline 2023. & 89204 \\
\hline 2024. & 96891 \\
\hline 2025. & 105502 \\
\hline
\end{tabular}


Prema prognozi prikazanoj u tablici, vidljivo je da bi broj novih članova OMF-a iz 2018. bio dosegnut tek 2024.

\section{Korelacijska i regresijska analiza uplata doprinosa u MIO II i broja novih članova OMF-a}

Dodatno je izvršena korelacijska i regresijska analiza u svrhu utvrđivanja odnosa između uplata doprinosa u MIO II i broja novih članova OMF-a za razdoblje od 2011. do 2020. Prikupljeni podaci prikazani su u tablici 4.

Tablica 4. Uplate doprinosa u MIO II i broj novih članova OMF-a.

\begin{tabular}{|ccc|}
\hline Godina & Broj novih članova OMF-a & $\begin{array}{c}\text { Iznos uplata doprinosa u MIO II } \\
\text { u milijardama kn }\end{array}$ \\
\hline 2011. & 46217 & 4,79 \\
\hline 2012. & 52995 & 4,98 \\
\hline 2013. & 53825 & 5,30 \\
\hline 2014. & 42727 & 4,95 \\
\hline 2015. & 56988 & 5,20 \\
\hline 2016. & 59893 & 5,36 \\
\hline 2017. & 65940 & 5,72 \\
\hline 2018. & 101181 & 6,20 \\
\hline 2019. & 83354 & 6,69 \\
\hline 2020. & 59267 & 6,88 \\
\hline
\end{tabular}

\subsection{Korelacijska analiza}

Odnos broja novih članova OMF-a i uplata doprinosa u MIO II prikazan je na grafikonu 5.

Grafikon 5. Dijagram rasipanja uplata doprinosa u MIO II i broja novih članova OMF-a

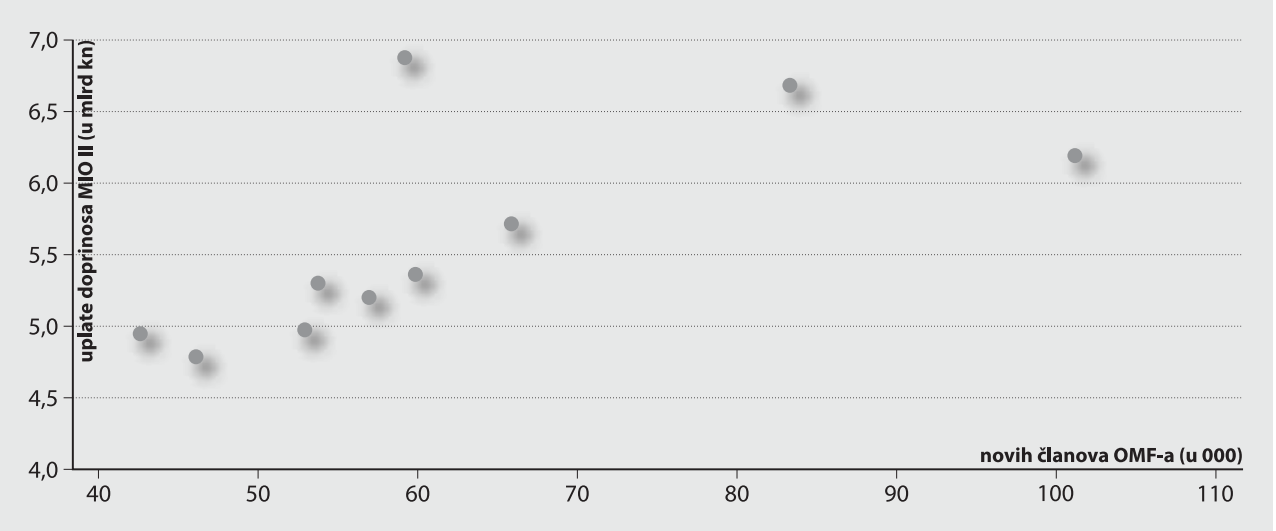


Već iz dijagrama rasipanja vidljivo je da je korelacija između promatranih varijabli pozitivna i umjereno visoka. Kao mjera povezanosti izračunat je Pearsonov koeficijent korelacije. Dobivena vrijednost $(r=0,67 ; \mathrm{p}<0,05)$ ukazuje na pozitivnu i statistički značajnu povezanost između promatranih varijabli. Povećanjem broja novih članova OMF-a povećava se i iznos uplate doprinosa u MIO II, što je i logično. Koeficijent determinacije $\left(\mathrm{R}^{2}\right)$ iznosi 0,4489 , što znači da je oko $45 \%$ varijance uplata doprinosa u MIO II objašnjeno brojem novih članova OMF-a. Iz toga proizlazi da na iznos uplata doprinosa u MIO II znatno utječu i neki drugi faktori, o čemu bi trebalo napraviti dodatnu analizu.

\subsection{Regresijska analiza}

U svrhu daljnje analize povezanosti između broja novih članova OMF-a i uplata doprinosa u MIO II provedena je regresijska analiza. Takav postupak opravdan je prethodno utvrđenoj statističkoj značajnosti koeficijenta korelacije. Analizirana su tri regresijska modela: linearni, eksponencijalni i dvostruko logaritamski regresijski model. $\mathrm{Na}$ temelju koeficijenta determinacije utvrđeno je da je najreprezentativniji dvostruko logaritamski regresijski model te će on biti detaljnije objašnjen.

Grafikon 6. Jednadžba dvostruko logaritamskog modela regresije (POWER) iz dijagrama rasipanja: odnos uplata doprinosa u MIO II i broja novih članova OMF-a 2011. - 2020.

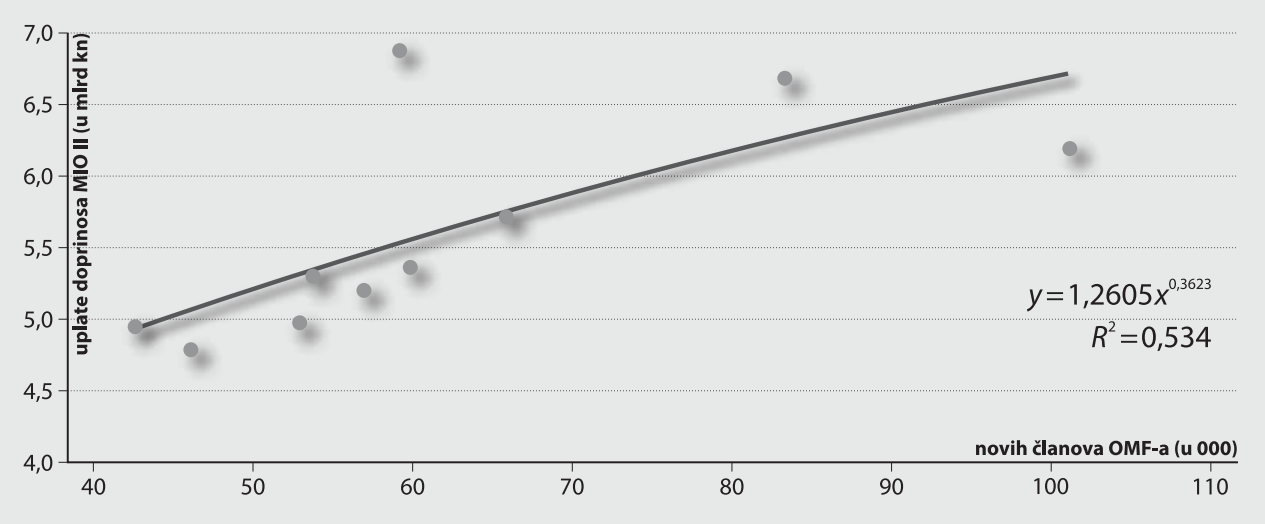

Dobivena jednadžba dvostruko logaritamskog modela regresije (POWER) glasi:

$$
Y=1,2605 x^{0,3623}
$$

pri čemu je

$X$ - broj novih članova OMF-a u tisućama

$Y$ - uplate doprinosa u MIO II u milijardama kn.

Iz jednadžbe je vidljivo da se s povećanjem broja novih članova OMF-a za $1 \%$ očekuje povećanje uplata doprinosa u MIO II za 0,36 \% (funkcija koja pokazuje zavisnost uplata doprinosa u MIO II o broju novih članova OMF-a je neelastična). 
Koeficijent determinacije $\left(\mathrm{R}^{2}=0,534\right)$ ukazuje na to da je $53,40 \%$ veze između promatranih varijabli objašnjeno dvostruko logaritamskim regresijskim modelom. Model je statistički značajan $(\mathrm{p}<0,05)$.

Dobiveni regresijski model omogućava procjenu izosa uplate doprinosa u MIO II za određeni broj novih članova OMF-a. Naprimjer, ako bi broj novih članova OMF-a bio 120 000, očekivane uplate doprinosa u MIO II iznosile bi 7,14 milijardi kn $\left(1,2605 \cdot 120^{0,3623}\right)$.

\section{Zaključak}

Primjenom statističkih metoda analize kretanja broja novih članova OMF-a u RH u razdoblju od 2011. do 2020. uz korištenje metode prognostičkih trend modela te individualnih indeksa otvara se mogućnost prognoziranja kretanja broja novih članova OMF-a u narednim godinama, kao i mogućnost mjerenja dinamike kretanja broja novih članova OMF-a. Pomoću statističkih metoda korelacijske i regresijske analize prikazana je i dokazana međuzavisnost promatranih varijabli, broja novih članova OMF-a i uplata doprinosa u MIO II te je određen i njihov međusobni utjecaj.

Na temelju dobivenih rezultata može se prognozirati trend kretanja promatranih varijabli, kao i izračunati očekivane vrijednosti u narednim godinama, pa se politika ulaganja obveznih mirovinskih fondova može prilagoditi uzimajući u obzir statistič$\mathrm{ku}$ analizu.

Ovaj je rad samo koračić u analizi koja bi trebala biti znatno obuhvatnija, a u svrhu stabilizacije mirovinskog sustava u Republici Hrvatskoj te u konačnici i povećanja mirovina.

\section{Literatura}

1. Hrvatska agencija za nadzor financijskih usluga. www.hanfa.hr. 10. siječnja 2020.

2. Papić, M. 2014. Primjenjena statistika u MS Excelu za ekonomiste, znanstvenike i neznalice. 5. izdanje. Zagreb: Zoro d.o.o.

3. Središnji registar osiguranika. www.regos.hr. 21. listopada 2019. 


\title{
Statistical analysis of trends in the number of mandatory pension funds participants and contribution payments into the second pension pillar in the Republic of Croatia
}

$$
\text { (2011-2020) }
$$

\begin{abstract}
Pension funds are major institutional investors in the Republic of Croatia, and their investment potential is continuously on the rise. In the past ten years, their share in the total assets of the financial system has increased from just under $5 \%$ to $17 \%$, while the assets of mandatory pension funds amount to about $27 \%$ of Croatia's GDP.Contribution payments to mandatory pension funds are obligatory for all employed citizens under the age of 40 , and the pension payments are calculated as $20 \%$ of the gross salary. Specifically, $15 \%$ is paid into the first pension pillar (intergenerational solidarity), and 5\% into the second pension pillar (individual capitalized savings). This paper includes a statistical analysis of trends in the number of mandatory pension funds participants, as well as payment dynamics of pension contributions based on individual capitalized savings in the second pension pillar in Croatia from 2011 to 2020, along with the impact and interrelations of said variables.
\end{abstract}

Key words: pension funds, pension insurance, intergenerational solidarity, capitalized savings 